\title{
The heterogeneous reaction of hydroxyl radicals with sub-micron squalane particles: a model system for understanding the oxidative aging of ambient aerosols
}

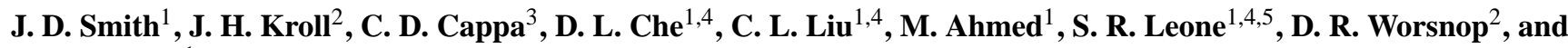 \\ K. R. Wilson ${ }^{1}$ \\ ${ }^{1}$ Chemical Sciences Division, Lawrence Berkeley National Laboratory, Berkeley, CA 94720, USA \\ ${ }^{2}$ Aerosol and Cloud Chemistry, Aerodyne Research Inc., Billerica, MA 01821, USA \\ ${ }^{3}$ Department of Civil and Environmental Engineering, University of California, Davis, CA 95616, USA \\ ${ }^{4}$ Department of Chemistry, University of California, Berkeley, CA 94720, USA \\ ${ }^{5}$ Department of Physics, University of California, Berkeley, CA 94720, USA
}

Received: 26 November 2008 - Published in Atmos. Chem. Phys. Discuss.: 5 February 2009

Revised: 30 April 2009 - Accepted: 1 May 2009 - Published: 18 May 2009

\begin{abstract}
The heterogeneous reaction of $\mathrm{OH}$ radicals with sub-micron squalane particles, in the presence of $\mathrm{O}_{2}$, is used as a model system to explore the fundamental chemical mechanisms that control the oxidative aging of organic aerosols in the atmosphere. Detailed kinetic measurements combined with elemental mass spectrometric analysis reveal that the reaction proceeds sequentially by adding an average of one oxygenated functional group per reactive loss of squalane. The reactive uptake coefficient of $\mathrm{OH}$ with squalane particles is determined to be $0.3 \pm 0.07$ at an average OH concentration of $\sim 1 \times 10^{10}$ molecules $\mathrm{cm}^{-3}$. Based on a comparison between the measured particle mass and model predictions it appears that significant volatilization of a reduced organic particle would be extremely slow in the real atmosphere. However, as the aerosols become more oxygenated, volatilization becomes a significant loss channel for organic material in the particle-phase. Together these results provide a chemical framework in which to understand how heterogeneous chemistry transforms the physiochemical properties of particle-phase organic matter in the troposphere.
\end{abstract}

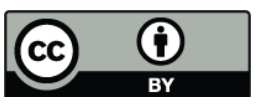

Correspondence to: K. R. Wilson (krwilson@lbl.gov)

\section{Introduction}

Heightened concern over global climate change has led to increased scrutiny of the direct and indirect effects of aerosols on radiative forcing. Aerosol particles scatter and absorb solar radiation as well as nucleate clouds, thus altering the Earth's radiation budget. Particle size and chemical composition can be important factors in determining the magnitude of these effects (Dusek et al., 2006; Shilling et al., 2007). Organic material, which comprises a significant fraction (20$90 \%$ ) of the total fine aerosol mass in the lower troposphere (Seinfeld and Pandis, 1998; Kanakidou et al., 2005), can be readily oxidized by gas-phase compounds such as $\mathrm{OH}, \mathrm{O}_{3}$, $\mathrm{NO}_{3}$, etc. It has been shown that these heterogeneous reactions of organic aerosols can alter both composition and size, in some cases activating the particles for cloud formation (Shilling et al., 2007; Broekhuizen et al., 2004). Furthermore, oxidative aging of organic aerosols may also liberate a host of volatile organic compounds (VOCs) that are potentially important intermediates in photochemical cycles such as smog formation (Molina et al., 2004; Kwan et al., 2006).

The hydroxyl radical $(\mathrm{OH})$ is the most important reactive species in both clean and polluted atmospheres (Seinfeld and Pandis, 1998). Key steps in photochemical smog formation involve $\mathrm{OH}$ radical reactions that, in the presence of $\mathrm{NO}_{\mathrm{x}}$, functionalize hydrocarbons and lead to the formation of tropospheric ozone (Finlayson-Pitts and Pitts, 2000).

Published by Copernicus Publications on behalf of the European Geosciences Union. 


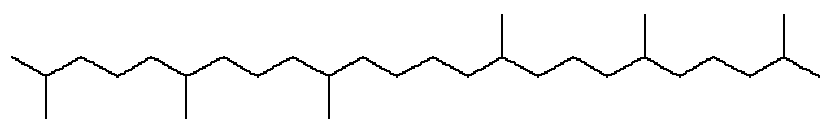

Fig. 1. Chemical structure of squalane.

The atmospheric importance of these cycles has led to an enormous experimental and theoretical effort, which has produced $\mathrm{OH}$ reaction rates and mechanisms that are relatively well-understood (Aschmann et al., 2001; Atkinson, 1997, 2003; Atkinson et al., 2004; D'Anna et al., 2001; FinlaysonPitts and Pitts, 2000; Seinfeld and Pandis, 1998). Reaction rates and mechanisms of hydrocarbon free radicals in the condensed-phase have been similarly well-studied (Avila et al., 1993; Bennett and Summers, 1974; Ferenac et al., 2003; Fokin and Schreiner, 2002; Ingold, 1969; Russell, 1957; Vonsonntag and Schuchmann, 1991). However, it remains unclear how well these gas and condensed-phase chemical mechanisms apply to the more complex heterogeneous reactions of $\mathrm{OH}$ radicals with organic aerosol particles.

Only recently have investigators begun to examine in detail the reactivity of organic aerosols with $\mathrm{OH}$ in the presence of $\mathrm{O}_{2}$ (termed aging) (Bertram et al., 2001; Molina et al., 2004; George et al., 2007; McNeill et al., 2008; Hearn and Smith, 2006; Lambe et al., 2007). Despite this effort, numerous outstanding questions still remain regarding both the rate and chemical mechanism of these reactions. For example, Molina et al. (2004) exposed a organic monolayer film to $\mathrm{OH}$ radicals resulting in the rapid removal of the monolayer through the production of gas-phase reaction products (i.e. volatilization). Molina et al. (2004) concluded that radical reactions may play an important role in the removal of organic particles from the troposphere on time scales comparable to rainout ( $\sim 6$ days). In a similar study, Vlasenko et al. (2008) found that the $\mathrm{OH}$ oxidation of stearic acid films produced appreciable quantities of gas-phase $\mathrm{C}_{2}-\mathrm{C}_{13}$ aldehydes, ketones, and carboxylic acids. Based on these kinds of experiments, it was further estimated that heterogeneous $\mathrm{OH}$ chemistry might be an important source of tropospheric gas-phase VOCs (Molina et al., 2004; Kwan et al., 2006). These results are in contrast with a number of recent studies performed on sub-micron organic particles that reported significantly less volatilization upon exposure to $\mathrm{OH}$ (Hearn et al., 2007; George et al., 2007; McNeill et al., 2008) or $\mathrm{NO}_{3}$ (Docherty and Ziemann, 2006) radicals. While the origin of this discrepancy remains unresolved, it may result from subtle differences in the $\mathrm{OH}$ reactivity of low pressure organic monolayers or films versus submicron aerosols.

The role of secondary chemistry in the $\mathrm{OH}$ oxidation of organic aerosols also remains unclear. Recent measurements indicate that the effective reactive uptake coefficient $(\gamma)$ for $\mathrm{OH}$ (Hearn and Smith, 2006) and Cl (Hearn et al., 2007) on dioctyl sebacate (DOS) particles is significantly larger than unity ( 2.0 and 1.7 , respectively). An effective uptake coeffi- cient is the fraction of gas-particle collisions which result in reaction, as measured from the loss of some particle-phase reactant. A value larger than unity indicates that each gasparticle collision results in the loss of more than one particlephase molecule, and is typically interpreted as indicating particle-phase secondary chain chemistry. Although an explicit chemical mechanism for secondary chemistry remains unclear, it has been suggested that radical oxidation products can react with molecular species, functionalizing the particle while simultaneously propagating the radical chain (Hearn et al., 2007). Such secondary chemistry can significantly accelerate the rate of particle oxidation, and therefore secondary chemistry may play a considerable role in the chemical transformation of ambient aerosols. A recent study by McNeill et al. (2008) on the $\mathrm{OH}$ oxidation of solid palmitic acid particles also reported evidence for secondary chemistry. Although in this study the uptake coefficient was found to be between $0.8-1$, the presence of secondary chemistry was inferred from a four parameter model fit to the kinetic data. Another study by George et al. (2007), using DOS particles, reported an uptake coefficient larger than one (1.3 \pm 0.4$)$, but concluded, within their experimental uncertainty, that there was no strong indication of secondary chemistry. Thus there appears little consensus on the relative importance of secondary particle-phase chemistry. This is in part due to the experimental difficulty in ascertaining exactly what fraction of the reactive uptake coefficient is due to the heterogeneous reaction with $\mathrm{OH}$ and what portion is due to homogeneous secondary chemistry occurring inside the particle. To do this may require a comprehensive analysis of the reactive uptake coefficient at various $\mathrm{OH}$ concentrations combined with a detailed understanding of how various oxidation products are formed within the particle.

Here we present an in-depth investigation of the heterogeneous oxidation of liquid squalane $\left(\mathrm{C}_{30} \mathrm{H}_{62}\right)$ particles by $\mathrm{OH}$ radicals. This current paper is primarily focused on the reactive uptake of $\mathrm{OH}$ radicals, formation and evolution of oxidation products, and particle volatilization. The effects of secondary chemistry, which become important at much lower $\mathrm{OH}$ concentrations, will be considered explicitly in a forthcoming paper (Smith et al., 2009). Squalane, shown in Fig. 1, is a branched alkane, containing 8 primary, 16 secondary and 6 tertiary carbon atoms. As such it is an ideal model system to represent the variety of reactive carbon sites that can occur in ambient organic aerosols. By combining a photochemical aerosol flow reactor with a high-resolution time-offlight aerosol mass spectrometer (HR-ToF-AMS) and a vacuum ultraviolet (VUV) photoionization AMS, we investigate $\mathrm{OH}$ heterogeneous chemistry in unprecedented detail. This is done by employing mass spectrometric elemental analysis (Aiken et al., 2008) as well as detailed kinetic measurements, which facilitate the formulation of an oxidation model that accounts for how squalane and its oxidation products evolve during reaction with $\mathrm{OH}$. Furthermore, this detailed analysis of the production and evolution of the $\mathrm{OH}$ oxidation 
products reveal new details of the explicit chemical mechanism of heterogeneous oxidation. In addition, we use the measured aerosol particle mass compared with model predictions to estimate the degree of particle volatilization.

\section{Experimental}

An atmospheric pressure flow tube reactor, detailed in Fig. 2, is used to investigate the heterogeneous oxidation of squalane particles. Squalane particles are formed by homogeneous nucleation in a $\mathrm{N}_{2}$ stream flowing through a $\sim 45 \mathrm{~cm}$ long Pyrex tube containing liquid squalane. The Pyrex tube is heated in a tube furnace to $\sim 125^{\circ} \mathrm{C}$ producing a log-normal particle size distribution with a geometric standard deviation of $\sim 1.3$, and a mean surface-weighted diameter of $\sim 160 \mathrm{~nm}$. The relative humidity is fixed at $30 \%$ with humidified $\mathrm{N}_{2}$ after which $\mathrm{O}_{2}(5 \%)$, trace hexane, and variable amounts of $\mathrm{O}_{3}$ are added to the aerosol stream. Ozone is generated by passing a $\mathrm{N}_{2} / \mathrm{O}_{2}$ mixture through a separate cell containing a Hg pen-ray lamp (UVP, LLC.) that is $22.9 \mathrm{~cm}$ in length. In this cell the $\mathrm{O}_{3}$ concentration is varied by changing the $\mathrm{N}_{2} / \mathrm{O}_{2}$ dilution ratio and measured using an ozone monitor (2B Technologies Inc.). The mixed gases and particles are passed through a $130 \mathrm{~cm}$ long, $2.5 \mathrm{~cm}$ inner diameter type 219 quartz reaction cell. OH radicals are generated along the length of the reaction cell using four continuous output $130 \mathrm{~cm}$ long $\mathrm{Hg}(\lambda=254 \mathrm{~nm})$ lamps (UVP, LLC.) positioned just outside and along the length of the reactor. The flow tube is actively cooled using pressurized air directed perpendicularly at three points along the length of the tube. However, due to the close proximity of the $\mathrm{Hg}$ lamps, the flow tube is still heated to approximately $35^{\circ} \mathrm{C}$. The total flow through the flow tube is fixed at $1.0 \mathrm{~L} / \mathrm{min}$, which, based upon the illuminated portion of the flow tube, corresponds to a reaction time of $37 \mathrm{~s}$.

Upon exiting the reactor a portion of the aerosol stream is sampled into a custom built aerosol mass spectrometer (AMS) that measures aerosol composition by thermally vaporizing the aerosol followed by tunable VUV photoionization as detailed in Gloaguen et al. (2006). For the experiments reported here, the aerosol is vaporized and photoionized by $10.2 \mathrm{eV}$ radiation produced by the Chemical Dynamics Beamline at the Advanced Light Source. For select experiments a high resolution time-of-flight aerosol mass spectrometer (HR-ToF-AMS, Aerodyne Research Inc.) (DeCarlo et al., 2006) is used. While most of the HR-ToF-AMS results presented here use electron impact (EI) ionization, the instrument was modified somewhat to accommodate tunable VUV ionization as well. To allow light to enter the instrument, the detection region is physically coupled to the beamline. The EI filaments (typically on either side of the ionization chamber) were removed and one was replaced below facing upwards. This allows VUV light from the beamline to freely pass through the ionization zone. During EI operation the

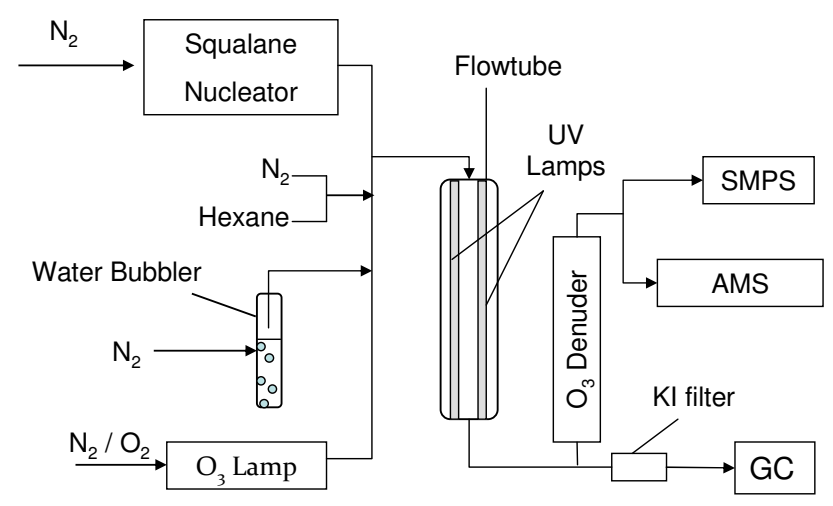

Fig. 2. A schematic view of the atmospheric pressure flow reactor employed in the heterogeneous oxidation of squalane aerosol. Squalane particles are produced in a nucleator. The aerosol stream is then mixed with hexane, humidified $\mathrm{N}_{2}, \mathrm{O}_{2}$, and $\mathrm{O}_{3}$. The aerosol stream enters an atmospheric pressure flow tube for reaction with $\mathrm{OH}$ radicals formed by the photolysis of ozone in the presence of $\mathrm{H}_{2} \mathrm{O}$. Upon exiting the reactor the aerosols are analyzed by a scanning mobility particle sizer (SMPS) and a by a aerosol mass spectrometer (AMS). Gas-phase concentrations of hexane are monitored during the reaction by a gas chromatograph (GC).

particles are vaporized at $600^{\circ} \mathrm{C}$, while for VUV operation the oven temperature is set to $100-150^{\circ} \mathrm{C}$ to help preserve the molecular ions in the mass spectrum.

The HR-ToF-AMS is used to measure the oxygen/carbon $(\mathrm{O} / \mathrm{C})$ molar ratios of the particulate organics (Aiken et al., 2007; Aiken et al., 2008). At the resolution of the mass spectrometer $(\sim 6000)$, the formulae of all organic ions below $m / z 100$ can be unambiguously assigned. From these formulae, plus the integrated intensities of the peaks, the relative number of $\mathrm{O}$ and $\mathrm{C}$ atoms within the particle can be determined. Because the carrier gas was free of gas-phase $\mathrm{CO}_{2}$, all of the $\mathrm{CO}_{2}^{+}$signal was assumed to originate from particulate organics; however, water-derived ions $\left(\mathrm{H}_{2} \mathrm{O}^{+}, \mathrm{OH}^{+}\right.$, and $\mathrm{O}^{+}$) may also have inorganic sources, so their contributions to organic signal were estimated using the multiplicative relation between $\mathrm{CO}_{2}^{+}$and $\mathrm{H}_{2} \mathrm{O}^{+}(0.225)$ suggested by Aiken, et al. (2008) All of the AMS signal could be adequately fit by using ions composed only of $\mathrm{C}, \mathrm{O}$, and $\mathrm{H}$ atoms; as expected, no other elements were detected in the particles.

As demonstrated by Aiken, et al. (2007, 2008), the elemental ratios determined from EI need to be corrected for biases arising from ion fragmentation within the mass spectrometer. Here we apply the empirical multiplicative factor of 1.33 to all $\mathrm{O} / \mathrm{C}$ measurements (Aiken et al., 2008). The error for elemental analysis using this technique has been estimated at $\sim 30 \%$ (Aiken et al., 2008), but is likely substantially better in this case. This is because the starting material has a known $\mathrm{O} / \mathrm{C}$ ratio $(0)$ and therefore it is only necessary to measure the change in $\mathrm{O} / \mathrm{C}$ ratio. Incremental changes in $\mathrm{O} / \mathrm{C}$ can be measured with reasonably high precision (Aiken et al., 
2008). Additionally, the multiple oxidation reactions form a complex mixture of a large number of products, for which the correction factors determined by Aiken, et al. $(2007,2008)$ are likely to be the most valid, due to the averaging of multiple correction factors from individual molecules.

The remainder of the aerosol stream not sampled by the AMS is split such that a fraction of the flow is sent to a gas chromatograph (GC) equipped with a flame ionization detector (SRI Instruments) for measuring the average $\mathrm{OH}$ concentration (described below), and a scanning mobility particle sizer (SMPS, TSI model 3936) to measure particle size distributions and number concentration. $\mathrm{OH}$ radicals are generated within the atmospheric pressure flow tube by the photolysis of ozone in the presence of water vapor. The flow tube is made of type 219 quartz, which blocks UV wavelengths $<220 \mathrm{~nm}$, to eliminate the direct production of $\mathrm{O}_{3}$ from $\mathrm{O}_{2}$ within the reactor. The $\mathrm{OH}$ concentration is controlled by adjusting the ozone concentration within the flow cell. The time averaged concentration of $\mathrm{OH}$ in the flow tube is measured via a gas-phase reference compound using a mixed phase relative rate method similar to the one recently described by Hearn and Smith (2006). The reference compound used in these experiments is hexane $\left(\mathrm{C}_{6} \mathrm{H}_{14}\right)$, which reacts with $\mathrm{OH}$ radicals with a rate constant of $5.2 \times 10^{-12} \mathrm{~cm}^{3} \mathrm{molec}^{-1} \mathrm{~s}^{-1}$ (Atkinson, 2003). The initial hexane concentration entering the reactor is typically $75 \mathrm{ppb}-120 \mathrm{ppb}$. The loss of hexane, due to reaction with $\mathrm{OH}$, is measured by monitoring the hexane concentration exiting the flow tube using a GC. The hexane is pre-concentrated for $3 \mathrm{~min}$ in a Tenax-GR absorbent trap before analysis by the GC. During typical operation, the portion of the flow directed to the GC is filtered to remove particles and passed through a small column packed with potassium iodide to remove ozone which can react with the absorbent trap.

The rate constant for the $\mathrm{OH}$ oxidation of squalane particles $\left(k_{S q}\right)$ is measured using a standard relative rate approach. The loss of particle-phase squalane, determined from the AMS spectrum, is directly compared with the loss of the reference compound hexane, determined from the GC peak area, both for the same fixed reaction time, using

$$
\ln \left([\mathrm{Sq}] /[\mathrm{Sq}]_{0}\right)=k_{\mathrm{Sq}}\left[\frac{\ln \left([\mathrm{Hex}] /[\mathrm{Hex}]_{0}\right)}{k_{\mathrm{Hex}}}\right] .
$$

Here $[\mathrm{Sq}]$ and $[\mathrm{Hex}]$ are the final concentrations of squalane and hexane exiting the flow tube after reaction with $\mathrm{OH}$, and $[\mathrm{Sq}]_{0}$ and $[\mathrm{Hex}]_{0}$ are the initial concentrations of squalane and hexane entering the flow tube. It should be noted that [Sq] represents the spatially averaged squalane concentration (i.e. the total number of squalane molecules per volume of gas), which is the quantity measured by the AMS. Since the second order rate constant $\left(k_{\mathrm{Hex}}\right)$ for the reaction of hexane with $\mathrm{OH}$ is known, the rate constant $\left(k_{\mathrm{Sq}}\right)$ for the reaction of particle-phase squalane with $\mathrm{OH}$ can be determined using Eq. (1). It is straightforward to show that the bracketed por- tion on the right hand side of Eq. (1) is equal to the average $\mathrm{OH}$ exposure $\left(\langle\mathrm{OH}\rangle_{t} \cdot t\right)$ as given below

$$
\frac{\ln \left([\mathrm{Hex}] /[\mathrm{Hex}]_{0}\right)}{-k_{\mathrm{Hex}}}=\int_{0}^{t}[\mathrm{OH}] d t=\langle\mathrm{OH}\rangle_{t} \cdot t .
$$

Here $[\mathrm{OH}]$ is the time dependent concentration of $\mathrm{OH}$, and $\langle\mathrm{OH}\rangle_{t}$ is the time averaged concentration of $\mathrm{OH}$. To derive a specific form of Eq. (1) that is most convenient for the kinetic analysis presented here, we substitute Eq. (2) into Eq. (1) and convert to the exponential form yielding

$$
\frac{[\mathrm{Sq}]}{[\mathrm{Sq}]_{0}}=\exp \left(-k_{\mathrm{Sq}}\langle\mathrm{OH}\rangle_{t} \cdot t\right)
$$

By plotting $[\mathrm{Sq}] /[\mathrm{Sq}]_{0}$ versus $\langle\mathrm{OH}\rangle_{t} \cdot t$, and fitting the data to an exponential, $k_{\mathrm{sq}}$ can be determined. The average $\mathrm{OH}$ exposure is varied by keeping the flow rate (i.e. reaction time) constant and varying the average $\mathrm{OH}$ concentration. The average $\mathrm{OH}$ concentration can be estimated by dividing the measured average $\mathrm{OH}$ exposure $\left(\langle\mathrm{OH}\rangle_{t} \cdot t\right)$ by the reaction time in the flow tube $(37 \mathrm{~s})$, and it ranges from 0 to $1 \times 10^{11} \mathrm{molec} \mathrm{cm}^{-3}$. The relative rate analysis relies on the assumption that the loss of hexane in the flow tube is dominated by the reaction with $\mathrm{OH}$ radicals. This assumption is verified using a kinetic model consisting of 32 possible reactions (Atkinson et al., 2004). It is found that $\mathrm{OH}$ accounts for more than $99 \%$ of the hexane lost during the reaction (i.e., losses by $\mathrm{O}$ atoms or other oxidants are negligible). As a final check a relative rate analysis of butane was conducted. Using the recommended value for $k_{\mathrm{Hex}}$ of $5.2 \times 10^{-12} \mathrm{~cm}^{3} \mathrm{molec}^{-1} \mathrm{~s}^{-1}$ (Atkinson, 2003) the rate constant for the reaction of butane with $\mathrm{OH}$ is found to be $(2.1 \pm 0.2) \times 10^{-12} \mathrm{~cm}^{3} \mathrm{molec}^{-1} \mathrm{~s}^{-1}$, which is well within error of the value $\left((2.36 \pm 0.47) \times 10^{-12} \mathrm{~cm}^{3} \mathrm{molec}^{-1} \mathrm{~s}^{-1}\right)$ reported by Atkinson (2003).

\section{Results and discussion}

In order to investigate the rate of heterogeneous oxidation of squalane particles by $\mathrm{OH}$, the decay in relative intensities of squalane ion peaks in the AMS mass spectrum are measured as a function of average $\mathrm{OH}$ exposure. The potential influence of photochemistry on the squalane reaction rate is explored by turning off half of the UV lamps and recovering the $\mathrm{OH}$ concentration by simply increasing the $\mathrm{O}_{3}$ precursor concentration. No evidence was found that the squalane reaction kinetics or product distributions depend upon the amount of UV light in the reactor, but rather they depend only on the concentration of $\mathrm{OH}$ in the flow cell.

Figure 3 shows a typical VUV-AMS spectrum of unreacted squalane particles (Fig. 3a), as well as the spectrum after exposure to $\mathrm{OH}$ in the flow tube (Fig. 3b). The two VUV ion peaks monitored during kinetic measurements, corresponding to the squalane parent molecular ion $(m / z=422)$ 


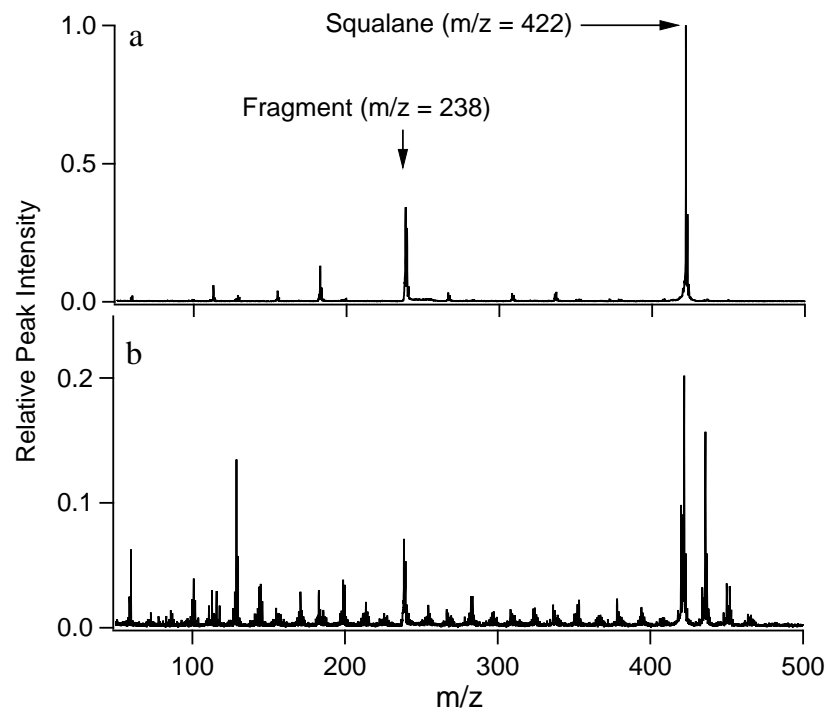

Fig. 3. The VUV AMS spectra of squalane aerosols, measured at a photoionization energy of $10.2 \mathrm{eV}$, (a) before and (b) after exposure to $\mathrm{OH}$ radicals $\left(\sim 1.2 \times 10^{12}\right.$ molec $\left.\mathrm{cm}^{-3} \mathrm{~s}\right)$. The mass spectra are normalized to the initial squalane parent peak intensity. The $m / z$ peaks monitored during the kinetic measurements are shown in the top panel. Higher molecular weight $(m / z>422)$ oxidation products can be seen in the oxidized spectrum (b).

and the largest fragment $(m / z=238)$, are indicated in the figure. Figure 4 shows the unit mass resolution EI spectrum (from the ToF-AMS) measured before and after $\mathrm{OH}$ oxidation. It should be pointed out that at nearly every nominal mass in the EI spectrum of the oxidized organics there are multiple fragment peaks originating from both squalane and the particle-phase oxidation products. For instance, at a nominal mass of 113 there are contributions from both a squalane fragment ion $\left(\mathrm{C}_{8} \mathrm{H}_{17}^{+}\right)$as well as two oxidation product fragments $\left(\mathrm{C}_{7} \mathrm{H}_{13} \mathrm{O}^{+}\right.$and $\left.\mathrm{C}_{6} \mathrm{H}_{9} \mathrm{O}_{2}^{+}\right)$. Here only the decay of the peak corresponding to $\mathrm{C}_{8} \mathrm{H}_{17}^{+}(m / z=113.13)$ is considered in the kinetic measurements. The interferences of multiple product ions are significantly reduced in the VUV mass spectra due to the limited fragmentation resulting from photoionization. Measuring the decay kinetics of squalane over the broad range of conditions outlined above (e.g. VUV parent ion vs. fragment ions, $100^{\circ} \mathrm{C}$ vs. $600^{\circ} \mathrm{C}$ oven temperature, EI vs. VUV) minimizes the potential for experimental artifacts and increases our overall confidence in the accuracy of the kinetic data. Of particular concern is the possibility that as the particles are oxidized they become less volatile, and the vaporization efficiency decreases leading to incomplete particle volatilization. This may be particularly important at the lower heater temperatures used for VUV analysis. However, it is found that the total ion signal in the AMS, when normalized to the SMPS particle volume and the VUV photon flux, is constant to within $10 \%$ over the entire range of $\mathrm{OH}$ exposures employed in the kinetic analysis presented here. This

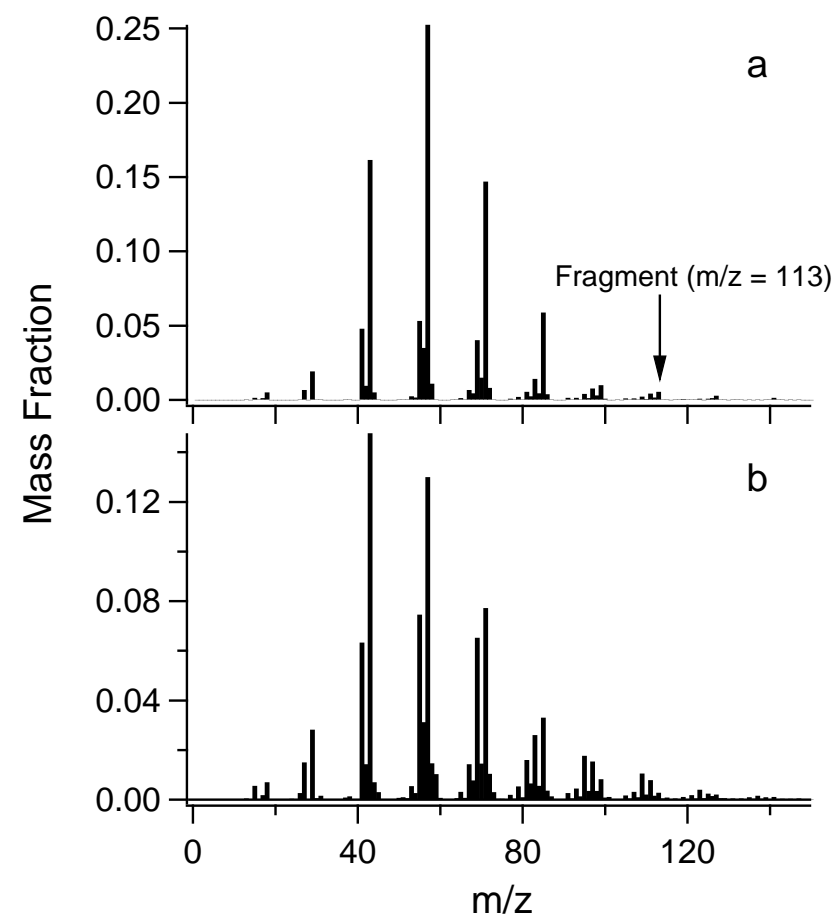

Fig. 4. The unit mass resolution electron impact spectra of squalane particles (from the HR-ToF-AMS before (a) and after (b) exposure to $\mathrm{OH}$ radicals $\left(\sim 1.2 \times 10^{12}\right.$ molec $\left.\mathrm{cm}^{-3} \mathrm{~s}\right)$. The observed differences in the two spectra are far more subtle than the VUV measurements. Kinetics measurements were performed using the fragment ion peak at $m / z=113.13$.

observation suggests that the particle vaporization efficiency is nearly unchanged over the course of the reaction. It is possible that a decrease in the vaporization efficiency could be compensated by an increase in the VUV cross-section of the particle-phase products, resulting in the near constant total ion signal. However, as shown below the good agreement between in the decay kinetics measured using EI at $600^{\circ} \mathrm{C}$ and VUV at $100^{\circ} \mathrm{C}$ indicate that incomplete vaporization of the particles is unlikely.

The parameter of interest in these heterogeneous kinetic measurements is the reactive uptake coefficient $\left(\gamma_{\mathrm{OH}}\right)$, defined as the fraction of $\mathrm{OH}$ collisions with the particle that result in a reaction. The gas-phase loss of $\mathrm{OH}$ is not directly measured here, but rather the reaction is monitored through the reactive loss of squalane in the particle-phase to obtain $\gamma_{\mathrm{OH}}^{\mathrm{Sq}}$. Here the superscript Sq denotes an uptake coefficient measured via the loss of squalane in the particle. If the reactive loss of squalane is due entirely to reactions with $\mathrm{OH}$, then $\gamma_{\mathrm{OH}}=\gamma_{\mathrm{OH}}^{\mathrm{Sq}}$ at early reaction times when the particle is primarily squalane. However, as the reaction progresses particle-phase oxidation products are formed, which may react with $\mathrm{OH}$ more rapidly or slowly than squalane resulting in an increase or decrease in $\gamma_{\mathrm{OH}}$ respectively. The heterogeneous reactivity of both squalane and its reaction products 
will be investigated in detail below. Furthermore, it is also possible that in addition to $\mathrm{OH}$, squalane may be consumed by particle-phase species such as radical intermediates. This type of secondary chemistry could potentially lead to an increase in the measured uptake coefficient as discussed previously (Hearn and Smith, 2006; Hearn et al., 2007; McNeill et al., 2008).

Determining the uptake coefficient by measuring the decay of squalane (or its fragments), in essence, narrows the definition of $\gamma_{\mathrm{OH}}^{\mathrm{Sq}}$ to the fraction of total $\mathrm{OH}$-particle collisions that result in a reaction with squalane. The value of $\gamma_{\mathrm{OH}}^{\mathrm{Sq}}$, defined in this manner, depends upon the extent of reaction, since the squalane concentration in the particle continually decreases, due to the reaction with $\mathrm{OH}$. An alternate definition of $\gamma_{\mathrm{OH}}^{\mathrm{Sq}}$ would be the fraction of $\mathrm{OH}$-squalane molecule collisions that result in a reaction. This definition accounts for the fact that the $\mathrm{OH}$ collision probability with squalane molecules in the particle decreases as the reaction proceeds and squalane is transformed into reaction products. Using this definition of $\gamma_{\mathrm{OH}}^{\mathrm{Sq}}$, the squalane reaction rate $(d[\mathrm{Sq}] / d t)$ is,

$\frac{d[\mathrm{Sq}]}{d t}=-\gamma_{\mathrm{OH}}^{\mathrm{Sq}} \cdot f \cdot J_{\mathrm{coll}} \cdot C_{p} \cdot A$.

where $f$ is the fraction of squalane molecules remaining within the particle (i.e. $[\mathrm{Sq}] /[\mathrm{Sq}]_{0}$ ) and depends on the extent of reaction. $J_{\text {coll }}$ is the $\mathrm{OH}$ flux at the particle surface, $A$ is the particle surface area, and $C_{p}$ is the particle number concentration. Here it has been assumed that the particle is well mixed on the timescale of the reaction, and therefore new squalane is constantly being replenished at the particle surface. The assumption of a well mixed particle will be discussed later in more detail. Equation (4) can be solved for $\gamma_{\mathrm{OH}}^{\mathrm{Sq}}$ by substituting $d[\mathrm{Sq}] / d t=-k_{\mathrm{Sq}} \cdot[\mathrm{Sq}] \cdot[\mathrm{OH}]$, $f=[\mathrm{Sq}] /[\mathrm{Sq}]_{0}$, and $J_{\mathrm{Coll}}=\bar{c} \cdot[\mathrm{OH}] / 4$ to obtain,

$\gamma_{\mathrm{OH}}^{\mathrm{Sq}}=\frac{k_{\mathrm{Sq}} \cdot[\mathrm{Sq}] \cdot[\mathrm{OH}]}{f \cdot J_{\mathrm{coll}} \cdot A \cdot C_{p}}=\frac{4 \cdot k_{\mathrm{Sq}} \cdot[\mathrm{Sq}]_{0}}{\bar{c} \cdot A \cdot C_{p}}$.

Here $k_{\mathrm{Sq}}$ is again the second order rate constant for the reaction of squalane with $\mathrm{OH}$ from Eq. (3), and $\bar{c}$ is the mean speed of gas-phase $\mathrm{OH}$. [Sq] is once again expressed as a spatially averaged concentration $\left(\operatorname{molec} \mathrm{cm}^{-3}\right)$ to represent the actual observable in the AMS. Equation (5) can be further simplified by expressing the spatially averaged squalane concentration in terms of the initial particle-phase density $\left(\rho_{0}=0.8 \mathrm{~g} \mathrm{~cm}^{-3}\right)$,

$[\mathrm{Sq}]_{0}=\frac{C_{p} \cdot V \cdot \rho_{0} \cdot N_{A}}{M_{\mathrm{Sq}}}$

where $V$ is the particle volume, $M_{\mathrm{Sq}}$ is the molar mass of squalane ( $422 \mathrm{~g} / \mathrm{mole}$ ), $N_{A}$ is Avogadro's number, and $C_{p}$ is defined above. The final expression for $\gamma_{\mathrm{OH}}^{\mathrm{Sq}}$ is,

$\gamma_{\mathrm{OH}}^{\mathrm{Sq}}=\frac{4 \cdot k_{\mathrm{Sq}} \cdot D_{\text {surf. }} \cdot \rho_{0} \cdot N_{A}}{\bar{c} \cdot 6 \cdot M_{\mathrm{Sq}}}$. where $V / A=D_{\text {surf. }} / 6$ and $D_{\text {surf. }}$ is the mean surfaceweighted particle diameter of the aerosol distribution measured by the SMPS. The surface-weighted diameter is used here since there is a log-normal distribution of particle diameters in the flow tube. The volume to surface area ratio $(V / A)$ for a log-normal distribution of particles is directly related to the surface weighted diameter as shown below:

$$
\frac{V}{A}=\frac{\int_{0}^{\infty} D^{3} f(D) d D}{6 \int_{0}^{\infty} D^{2} f(D) d D}=\frac{\bar{D} \operatorname{Exp}\left(\frac{5 \ln ^{2} \sigma}{2}\right)}{6}=\frac{D_{\text {surf. }}}{6} .
$$

Here $D$ is the particle diameter, and $f(D)$ is the normalized diameter distribution function given by

$$
f(D)=\frac{1}{\sqrt{2 \pi} D \ln \sigma} \operatorname{Exp}\left[\frac{-[\ln (D / \bar{D})]^{2}}{2 \ln ^{2} \sigma}\right] .
$$

where $\sigma$ is the geometric standard deviation and $\bar{D}$ is the median diameter of the log-normal distribution.

The mean surface-weighted particle diameter in Eq. (7) is assumed to be constant, and therefore volatilization is neglected. A numerical model of uptake kinetics is used to examine the potential errors in computing $\gamma_{\mathrm{OH}}^{\mathrm{Sq}}$ using Eq. (7) when particle volatilization occurs. For instance, if $80 \%$ of the particle mass is volatilized during the reaction, moderately non-exponential decay kinetics are observed in the model. In this case, using the average particle diameter measured over the course of the reaction and determining $k_{S q}$ by approximating the decay kinetics as a single exponential leads to an error of less than $3 \%$ in $\gamma_{\mathrm{OH}}^{\mathrm{Sq}}$. However, for the results presented here and detailed below virtually no particle volatilization is observed over the range of $\mathrm{OH}$ exposures used to compute $\gamma_{\mathrm{OH}}^{\mathrm{Sq}}$.

It has also been assumed in the derivation of Eq. (7) that the squalane decay rate $(d[\mathrm{Sq}] / d t)$ is proportional to the squalane concentration in the particle and therefore decays exponentially with $\mathrm{OH}$ exposure. Since $\mathrm{OH}$ is known to react rapidly with most organic compounds in the gas-phase, it can be safely assumed that the heterogeneous $\mathrm{OH}$ reaction with squalane should be a fast surface reaction (Rudich et al., 2007). This type of rapid surface reaction should result in an exponential decay of the particle-phase squalane as a function of $\mathrm{OH}$ exposure (Hearn et al., 2005). The decay in relative squalane peak intensity as a function of $\mathrm{OH}$ exposure from two separate experiments using VUV and EI ionization are shown in Fig. 5. The decay data in Fig. 5 are fit to Eq. (3) to obtain $k_{S q}$. Figure 5 clearly shows that the decay of squalane remains exponential over a large range where nearly $80 \%$ of the squalane is reacted within the particle, which confirms our original assumption that the reaction rate of squalane is indeed proportional to the squalane concentration in the particle. 
$\gamma_{\mathrm{OH}}^{\mathrm{Sq}}$ is computed via Eq. (7) using the decay constant, $k_{\mathrm{Sq}}$, obtained in the exponential fit of the kinetic data shown in Fig. 5. $\gamma_{\mathrm{OH}}^{\mathrm{Sq}}$ is corrected for gas-phase diffusion using the Fuchs and Sutugin formulation (Fuchs and Sutugin, 1970), parameterized by the OH gas-phase diffusion coefficient $\left(D_{\mathrm{OH}}\right)$. Here we use the same diffusion constant employed by George et al. (2007) $D_{\mathrm{OH}}=0.26 \mathrm{~cm}^{2} \mathrm{~s}^{-1}$, which leads to a $\sim 10 \%$ correction to the measured uptake coefficient. The diffusion corrected reactive uptake coefficient computed from 7 decay measurements is determined to be $0.30 \pm 0.07$, indicating that $30 \%$ of the $\mathrm{OH}$ collisions with squalane in the particle yield a reaction. The reactivity of subsequent oxidation products with $\mathrm{OH}$ will be considered below in order to draw general conclusions about whether the overall reactivity of the particle changes during the course of the reaction. The primary source of experimental uncertainty is $k_{\mathrm{Hex}}$ (Atkinson, 2003) used in the relative rate determination of the $\mathrm{OH}$ exposure axis (see Eq. 1).

It is important to note that the expression for the uptake coefficient given by Eq. (7) is a constant, which is slightly different than the more typical formulation (Katrib et al., 2005; George et al., 2007; Hearn and Smith, 2006), where the reactive uptake coefficient is assumed to vary with the extent of reaction. In this case, it is conventional to report an initial uptake coefficient $\left(\gamma_{0}\right)$, where $\gamma_{0}$ is obtained from a linear fit to a small subset of the decay data over a region where the initial concentration of the particle-phase species of interest has decayed by less than 10-30\% (George et al., 2007; Katrib et al., 2005). As expected for a single exponential an initial rate analysis of the decay data shown in Fig. 5 yields an uptake coefficient that is within $5 \%$ of the value determined from the full exponential fit $(0.30 \pm 0.07)$.

Although an uptake coefficient of 0.30 indicates that the heterogeneous oxidation of squalane is very efficient compared with gas-phase $\mathrm{OH}$ oxidation, it is considerably smaller than other recently reported values (Hearn and Smith, 2006; George et al., 2007; McNeill et al., 2008). For example, using a linear fit to the initial decay data as described previously, George et al. (2007) reported a reactive uptake coefficient of $1.3 \pm 0.4$ for the $\mathrm{OH}$ oxidation of DOS aerosol. Alternatively, if their entire kinetic trace (shown in Fig. 4 of George et al., 2007) is fit instead to an exponential function the uptake coefficient computed using Eq. (7) is 0.23, which is within error of the value reported here. Therefore, the raw data measured by George et al. (2007) is similar to what is reported here, and the differences in the uptake coefficients result in part from the fitting procedure used to compute the uptake coefficient. These differences occur because the decay of DOS as a function of $\mathrm{OH}$ exposure, observed by George et al. (2007), appears to behave bi-exponentially, with the first few data points, at small $\mathrm{OH}$ exposures, exhibiting a rapid decrease followed by a slower exponential decay. The origin of this bi-exponential behavior, which is not observed in the studies presented here, is unknown, but further studies

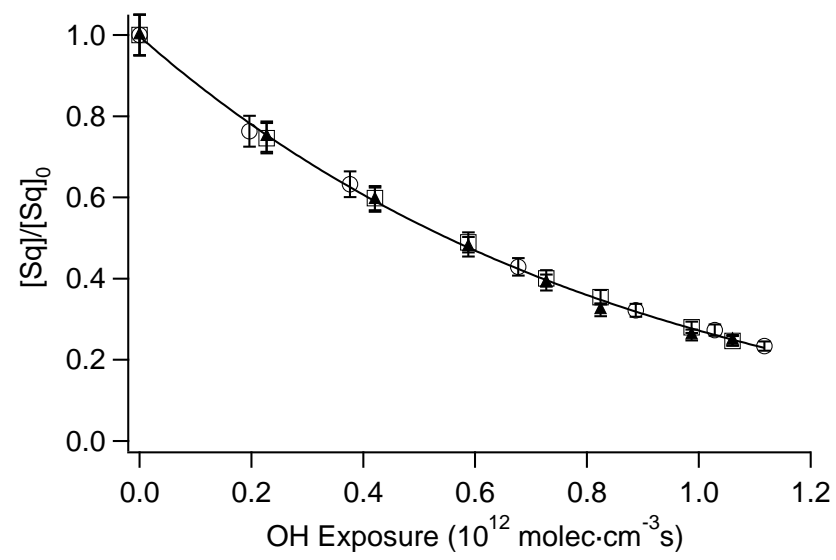

Fig. 5. The decay of squalane as a function of $\mathrm{OH}$ exposure. The kinetics were measured using two VUV ion peaks corresponding to the squalane parent molecular ion $(\square)(\mathrm{m} / \mathrm{z}=422)$ and the largest fragment ion $(\boldsymbol{\Delta})(m / z=238)$. In addition the $m / z=113.13(\bigcirc)$ peak in the high resolution electron impact spectrum (HR-ToF-AMS) is also used. The decay rate of all three ion peaks agree very well indicating minimal interference from underlying oxidation product peaks. The decay is fit to Eq. (3) (solid line) in order to determine the rate constant for the reaction of squalane with $\mathrm{OH}\left(k_{\mathrm{Sq}}\right)$, which is used to calculate the uptake coefficient $\left(\gamma_{\mathrm{OH}}^{\mathrm{Sq}}\right)$ using Eq. (7).

are underway to examine the heterogeneous kinetics at lower $\mathrm{OH}$ concentrations.

The uptake coefficient of $\mathrm{OH}$ on DOS reported by Hearn and Smith (2006) is also considerably larger (2.0) than what is reported here. However, their experiments were carried out in a nearly oxygen free environment in which ozone was present. These conditions could potentially lead to an enhanced uptake coefficient resulting from the reaction of ozone with particle-phase alkyl radicals (Paltenghi et al., 1984). In the presence of oxygen alkyl radicals will rapidly react with the $\mathrm{O}_{2}$ to form peroxy radicals. However, in the nearly oxygen free environment of the Hearn and Smith experiments it is possible that the alkyl radicals instead react with ozone which forms an alkoxy radical. This suggests that the chemistry in an oxygen free environment may be substantially different than in the presence of excess $\mathrm{O}_{2}$, and therefore good agreement between the results of Hearn and Smith and those presented here may not be expected.

The reactive uptake coefficient measured by McNeill et al. (2008) for $\mathrm{OH}$ on palmitic acid particles was reported to be $0.8-1$, and this was determined from a four parameter model fit to the kinetic data. If the 4 decay curves reported by McNeill et al. (2008) are fit to exponentials, 3 of the 4 uptake coefficients computed via Eq. (7) are between $0.28-0.39$ which are in reasonable agreement with the value reported here. However, the uptake coefficients calculated from the data of McNeill et al. seem to increase with decreasing particle diameter. We note that the palmitic acid particles studied by McNeill et al. are solid, and therefore 

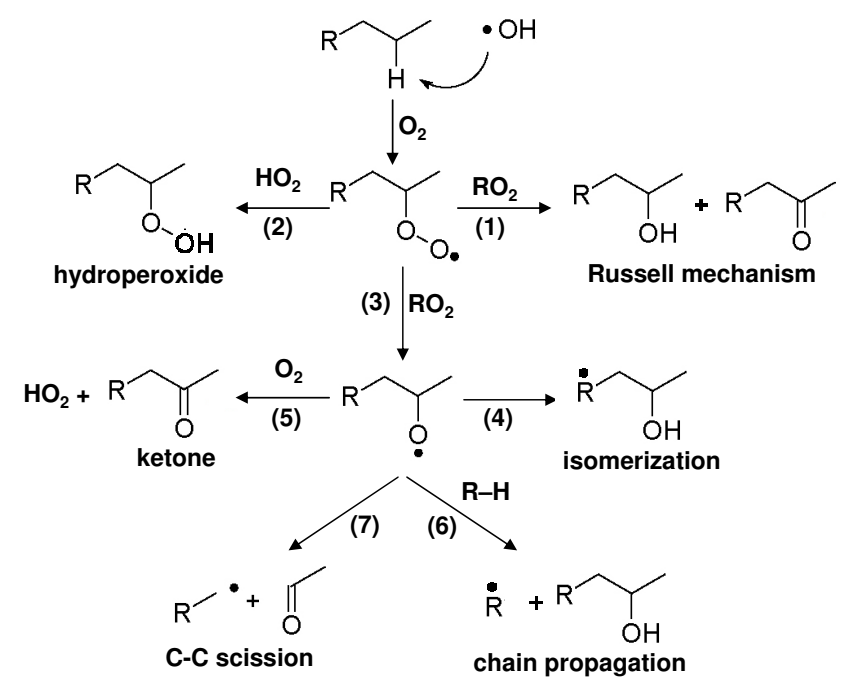

Fig. 6. A general reaction scheme for the $\mathrm{OH}$ oxidation of gas and condensed-phase hydrocarbons.

good agreement with the measurements on liquid squalane particles is not necessarily expected.

Furthermore, the average uptake coefficient $\left(\gamma_{\mathrm{OH}}\right)$ measured by Bertram et al. (2001) from the loss of gas-phase $\mathrm{OH}$ (as opposed to the loss of a particle-phase molecules) onto an alkane surface is 0.34. Due to gas-phase diffusion limitations the uncertainty in this measurement was relatively large, such that $\gamma_{\mathrm{OH}}$ values ranging from 0.16 to 1.0 could not be ruled out. In addition, Bagot et al. (2008) recently reported $\gamma_{\mathrm{OH}}$ to be $0.49 \pm 0.04$ for the reaction of superthermal $\mathrm{OH}$ on a squalane surface at low pressure. The slightly larger value for $\gamma_{\mathrm{OH}}$ from this measurement is potentially due to the increased translational energy of the $\mathrm{OH}$ radicals resulting in a larger reaction probability. Thus the uptake coefficient reported from gas-phase $\mathrm{OH}$ loss measurements appear to be relatively consistent with the particle-phase measurements presented here. The relatively good agreement between these gas-phase uptake measurements and those presented here (i.e. $\gamma_{\mathrm{OH}}^{\mathrm{Sq}} \approx \gamma_{\mathrm{OH}}$ ) suggest that secondary chemistry plays, at most, a minor role at least under the specific oxidation conditions examined here.

The decay of the squalane within the particle is accompanied by the formation of higher molecular weight oxidation products $(m / z>422)$. These products, formed by $\mathrm{OH}$ in the presence of $\mathrm{O}_{2}$, can be considered within the context of known reaction schemes, which include gas and liquidphase reaction mechanisms, as shown in Fig. 6 (George et al., 2007; Hearn et al., 2007; Molina et al., 2004). OH abstracts a hydrogen from squalane (R-H) forming an alkyl radical that rapidly forms a peroxy radical $\left(\mathrm{RO}_{2}\right)$ in the presence of $\mathrm{O}_{2}$. The $\mathrm{RO}_{2}$ radicals react through a sequence of intermediates to eventually form a variety of stable molecules that can include alcohols, hydroperoxides, ketones, and alde-

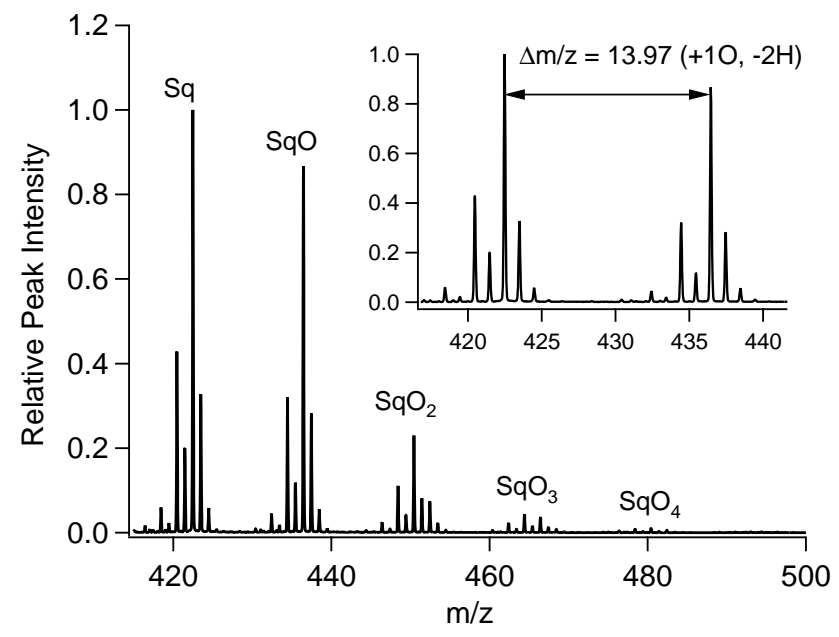

Fig. 7. The HR-ToF-AMS mass spectrum of reacted squalane showing the squalane oxidation products $\left(\mathrm{SqO}, \mathrm{SqO}_{2}, \mathrm{SqO}_{3}, \ldots, \mathrm{SqO}_{n}\right)$ measured at a VUV photon energy of $10.2 \mathrm{eV}$. Moving from lower to higher mass, each grouping shown corresponds to higher oxidation generations. Each ion peak in the $n$th generation grouping contains $\mathrm{n} \mathrm{O}$ atoms. The $\mathrm{O}$ atom content of each ion peak is determined by the mass difference from the squalane parent molecular ion as demonstrated in the inset.

hydes. The yield of these products as well as the number of oxygen functional groups that are added per reactive loss of squalane depend sensitively on which reaction pathways control the chemistry in the particle-phase. For example the Russell mechanism shown in Fig. 6 is thought to be important in the liquid (Russell, 1957) and aerosol-phase (Hearn et al., 2007). This reaction forms an equal number of alcohols and ketones, via the $\mathrm{RO}_{2}$ self reaction, with the net addition of one oxygen atom per reactive loss of squalane. In contrast, the $\mathrm{RO}_{2}+\mathrm{HO}_{2}$ channel produces a hydroperoxide by adding two oxygen atoms per reactive loss of squalane. The reaction mechanisms shown in Fig. 6 can be examined through a careful analysis of how many oxygen atoms are added per reactive loss of squalane. This type of analysis can potentially reveal the relative importance of specific pathways shown in Fig. 6.

The VUV HR-ToF-AMS mass spectrum of the observed oxidation products are shown in Fig. 7. The oxidation products appear in groups of 5-6 peaks spaced by $\Delta m / z \sim 14$. The first group of peaks, centered near $m / z=436$, corresponds to first generation oxidation products $(\mathrm{SqO})$. Each product peak in this group contains one oxygen atom, determined by the exact mass difference from the squalane parent peak, as shown in the inset of Fig. 7. At higher masses each successive group (centered at $450 \mathrm{amu}, 464 \mathrm{amu}$, etc.) is found to contain one additional $\mathrm{O}$ atom, corresponding to successively higher generations of oxidation products $\left(\mathrm{SqO}_{2}\right.$, $\mathrm{SqO}_{3}, \mathrm{SqO}_{4}, \ldots \mathrm{SqO}_{n}$ ). Based on the masses of the observed oxidation products it appears that they primarily correspond 
to carbonyls and alcohols. However, it is difficult to draw quantitative conclusions about the relative populations of specific species (e.g. alcohols vs. ketones) based on the relative peak intensities in the mass spectrum. The degree of fragmentation resulting from photoionization can be highly dependent on the identity of the parent molecule. For example, a relatively large product peak is observed at 2 mass units less than squalane $(m / z=420)$. This peak shows the same kinetic behavior as the first generation oxidation products, and likely corresponds to an alcohol fragment produced by water elimination during dissociative photoionization. Therefore, due to this uncertainty in the differing fragmentation probabilities, and possible differences in the photoionization cross sections, absolute product yields cannot be obtained from this data. We note that a similar set of oxidation products were observed by George et al. (2007) resulting from the radical oxidation of DOS particles. In addition, Hearn et al. (2007) also observed higher generation oxidation products from the $\mathrm{Cl}$ reaction with DOS particles.

The evolution of oxidation products is shown in Fig. 8. In order to access multiple generations of reaction, it is necessary to expose the particles to higher $\mathrm{OH}$ concentrations than were used in the kinetic determination of the uptake coefficient shown in Fig. 5. At these high $\mathrm{OH}$ exposures nearly all of the reference hexane in the system is removed resulting in large uncertainties in the relative rate measurements of average $\mathrm{OH}$ exposure. To circumvent this problem hexane is injected approximately $10 \mathrm{~cm}$ from the end of the flow tube such that it is only exposed to a constant fraction of the total $\mathrm{OH}$ in the flow tube. A single multiplicative factor, based on the squalane decay measured under the standard conditions described above, is then used to calibrate the fractional $\mathrm{OH}$ exposure to the total $\mathrm{OH}$ exposure. Therefore, the decay rate of squalane in Fig. 8 is rescaled to be identical to the lower exposure measurements shown in Fig. 5. For these measurements the focus is on the evolution of the oxidation products relative to squalane, which is of course independent of the exposure axis.

As can be seen in Fig. 8, $\mathrm{SqO}, \mathrm{SqO}_{2}$ and $\mathrm{SqO}_{3}$ each exhibit a complex dependence on $\mathrm{OH}$ exposure. Each oxidation product is formed at a different rate followed by a decay at higher $\mathrm{OH}$ exposures. The chemical evolution of these oxidation products are analyzed using a sequential oxidation model. In its simplest formulation, this model assumes that the rate coefficient for the $\mathrm{OH}$ reaction with squalane and subsequent oxidation products is the same, and furthermore each reaction results in the addition of a single $\mathrm{O}$ atom. Distinct chemical species, such as ketones or alcohols, are not distinguished in the model, but rather all the closed shell oxidation products are classified according to the number of $\mathrm{O}$ atoms (i.e. generation number). In addition, radical intermediates are not explicitly considered here, nor is volatilization. This model can be written as a sequence of $\mathrm{OH}$ reactions whose generalized form in the presence of $\mathrm{O}_{2}$ is,

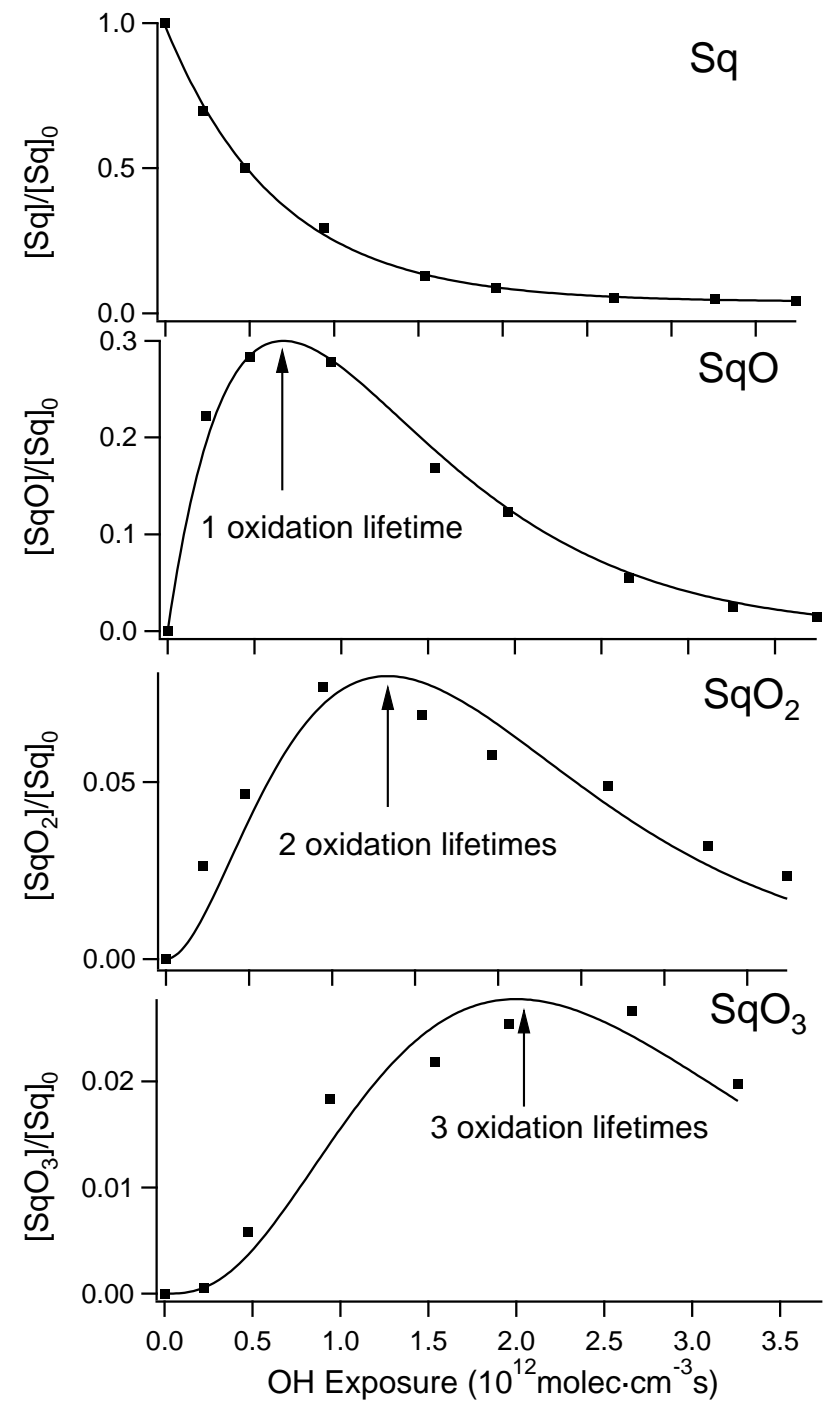

Fig. 8. The evolution of squalane and the first three generations of oxidation products $\left(\mathrm{SqO}, \mathrm{SqO}_{2}, \mathrm{SqO}_{3}\right)$ as a function of the average $\mathrm{OH}$ exposure. Each data set is fit to Eq. (9) (solid line) using the same rate constant $(k)$ as described in the text indicating that the oxidation products react with $\mathrm{OH}$ at the same rate as squalane. In addition, the position of the first, second, and third oxidation lifetimes, which are described in the text, are indicated in the figure.

$\mathrm{SqO}_{n}+\mathrm{OH} \stackrel{k}{\rightarrow} \mathrm{SqO}_{n+1}$

where $k$ is the second order rate constant and $n$ represents the oxidation generation. For unreacted squalane $n=0$. The integrated rate equation corresponding to Eq. (10) is,

$$
\frac{\left[\mathrm{SqO}_{n}\right]}{[\mathrm{Sq}]_{0}}=B_{n} \frac{(k \cdot\langle\mathrm{OH}\rangle \cdot t)^{n}}{n !} \operatorname{Exp}\left(-k \cdot\langle\mathrm{OH}\rangle_{t} \cdot t\right) \text {. }
$$

where $B_{n}$ is an adjustable parameter in the model to account for differences in VUV photoionization efficiency and fragmentation patterns of the oxidation products and squalane. The sequential oxidation model, represented by Eq. (11), is 


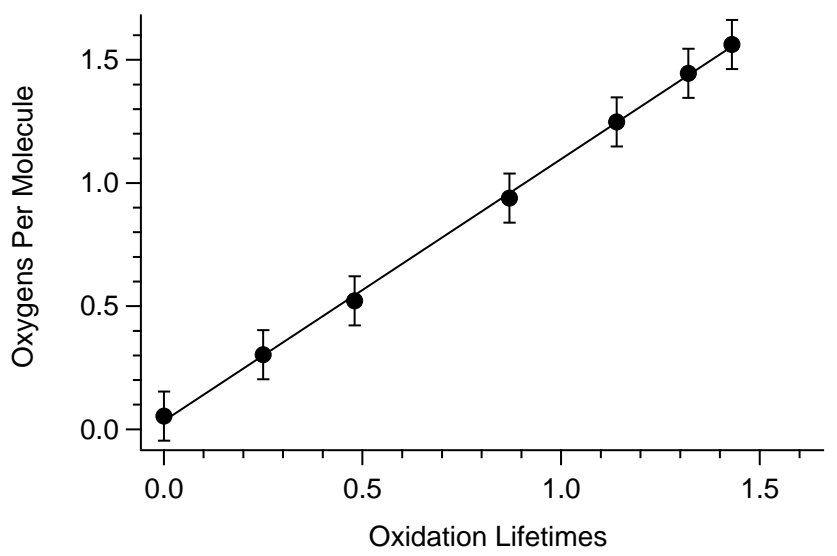

Fig. 9. The measured number of $\mathrm{O}$ atoms added per squalane molecule plotted as a function of oxidation lifetime. The number of $\mathrm{O}$ atoms per molecule is determined from the measured $\mathrm{O} / \mathrm{C}$ ratio multiplied by the number of carbons in squalane. The data is fit to a straight line and the slope is found to be $1.06 \pm 0.06$ indicating that approximately one $\mathrm{O}$ atom is added per reactive loss of squalane.

not directly based on the explicit chemical mechanism represented in Fig. 6, but is instead meant as a general representation of how squalane and its oxidation products evolve in the particle during the reaction.

Figure 8 shows the evolution of squalane and the first three generations $\left(\mathrm{SqO}, \mathrm{SqO}_{2}, \mathrm{SqO}_{3}\right)$ of oxidation products as a function of average $\mathrm{OH}$ exposure. The individual product species within a single generation have the same overall kinetic functional form, hence the largest two or three mass peaks within each group of masses are averaged to generate Fig. 8. To test whether this simple model can account for the chemical evolution of the oxidation products, the squalane decay is fit to Eq. (11), with $n=0$, to obtain the rate constant $(k)$. Subsequent oxidation products are then fit with Eq. (11) with $n$ characterizing the oxidation generation and $k$ fixed to the value determined from the fit to the squalane parent decay. The only adjustable parameter in the fits of Eq. (11) to the oxidation products is the amplitude $B_{n}$. The model fits shown in Fig. 8 represent the data well and show that, within experimental error, the chemical evolution of squalane and its oxidation products can all be represented by a single $k$. In other words, $\gamma_{\mathrm{OH}}^{\mathrm{Sq}} \approx \gamma_{\mathrm{OH}}^{\mathrm{SqO}} \approx \gamma_{\mathrm{OH}}^{\mathrm{SqO}_{2}} \approx \gamma_{\mathrm{OH}} \mathrm{SqO}_{3}$. This confirms our expectation that $\mathrm{OH}$ continues to react with the molecules in the particle even after much of the squalane is consumed by the reaction, indicating $\gamma_{\mathrm{OH}}^{\mathrm{Sq}} \approx \gamma_{\mathrm{OH}}$. This is perhaps not surprising since removing a small number of reactive sites (and replacing them with oxygen atoms) in a $\mathrm{C}_{30}$ alkane should not drastically diminish its reactivity towards $\mathrm{OH}$. At much larger $\mathrm{OH}$ exposures, however, this may not be the case as more reactive sites on the squalane molecule become increasingly functionalized.
Oxidation lifetime, denoted in Fig. 8, is determined by the average $\mathrm{OH}$ exposure divided by the kinetic lifetime $(\tau=1 / k)$ and represents the number of $\mathrm{OH}$ reactions with a particle divided by the number of molecules in that particle. The peak in the first generation oxidation product occurs at an oxidation lifetime of one. This is also the point where squalane has decayed to 1/e of its initial value. At one lifetime the number of reactions with $\mathrm{OH}$ is equal to the total number of molecules in the particle and according to the model an average of one $\mathrm{O}$ atom has been added to every molecule. In the same way, the peak in the second generation oxidation product $\left(\mathrm{SqO}_{2}\right)$ corresponds to a lifetime of two, where $[\mathrm{Sq}] /[\mathrm{Sq}]_{0}=1 / e^{2}$ and an average of two $\mathrm{O}$ atoms have been added to every molecule in the particle. Subsequent oxidation products, such as $\mathrm{SqO}_{3}$, can be described similarly. In general, the peak in a $\mathrm{SqO}_{n}$ oxidation product appears at the $1 / \mathrm{e}^{n}$ decay of squalane, or $n$ lifetimes, and provides further support that indeed $\gamma_{\mathrm{OH}}^{\mathrm{Sq}} \approx \gamma_{\mathrm{OH}}^{\mathrm{SqO}} \approx \gamma_{\mathrm{OH}}^{\mathrm{SqO}_{2}} \approx \gamma_{\mathrm{OH}}^{\mathrm{SqO}_{3}}$. If instead $\mathrm{OH}$ reacted substantially more quickly or slowly with $\mathrm{SqO}$ than $\mathrm{Sq}$, then the peak in $\mathrm{SqO}$ would occur at a lifetime either less than or greater than 1 respectively. The strong correlation between the squalane decay and the evolution of the oxidation products also indicates that the particle is well mixed, and that the products are not enhanced, relative to squalane, at the particle surface.

It is important to emphasize that there is always a statistical distribution of oxidation products within the particle and this distribution evolves over the course of the reaction. According to the model, at an oxidation lifetime of two the particle is composed of $13.5 \% \mathrm{Sq}, 27.0 \% \mathrm{SqO}, 27.0 \%$ $\mathrm{SqO}_{2}, 18.0 \% \mathrm{SqO}_{3}, 9.0 \% \mathrm{SqO}_{4}, 3.6 \% \mathrm{SqO}_{5} 1.2 \% \mathrm{SqO}_{6}$, $0.3 \% \mathrm{SqO}_{7}$, and so on, to give an average of two $\mathrm{O}$ atoms per squalane molecule. While the first and second generation products make up over $50 \%$ of the particle, a significant fraction of the particle is comprised of more oxygenated molecules functionalized with 3-7 $\mathrm{O}$ atoms. These kinds of molecules, although statistically improbable since they are at the tail end of the product distribution, could influence the physical properties of an aerosol such as its thermodynamic phase, hygroscopicity, or volatility.

To further confirm the chemical framework outlined in the oxidation model of the data presented above, the change in the atomic $\mathrm{O} / \mathrm{C}$ ratio is measured as a function of oxidation lifetime $\left(\langle\mathrm{OH}\rangle_{t} \cdot t / \tau\right)$ using the EI HR-ToF-AMS. The number of $\mathrm{O}$ atoms per molecule is then obtained by multiplying the measured $\mathrm{O} / \mathrm{C}$ ratios by the number of carbons in squalane $\left(N_{C}=30\right)$. This procedure assumes that no volatilization occurs due to the $\mathrm{OH}$ reaction. The validity of this assumption will be addressed below. Figure 9 shows the measured number of $\mathrm{O}$ atoms added to squalane versus the oxidation lifetime. A linear fit to this data yields a slope of $1.06 \pm 0.1$, confirming that an average of one oxygen atom is added per oxidation lifetime consistent with the product evolution measurements and model predictions shown in Fig. 8. 
The observation that only one oxygen atom is added per squalane consumed can help elucidate the rather complex mechanism shown in Fig. 6. For example, the Russell mechanism forms an alcohol and a ketone from the $\mathrm{RO}_{2}$ self reaction with the net addition of 1 oxygen functional group per reactive loss of squalane. In contrast, the $\mathrm{HO}_{2}+\mathrm{RO}_{2}$ reaction, discussed previously, appears to be at most a minor channel since the formation of the hydroperoxide product results in the addition of two oxygen atoms. This observation is consistent with the measurements of McNeill et al. (2008) who found no evidence for the hydroperoxide product from the $\mathrm{OH}$ reaction with palmitic acid particles. Furthermore, since $\mathrm{HO}_{2}$ reacts very slowly with most organics we do not expect that it will react directly with squalane or its stable oxidation products.

To explore the range over which the sequential oxidation model presented above is applicable, measurements are compared with model predictions over a very large range of oxidation lifetimes. Figure 10 shows the measured $\mathrm{O} / \mathrm{C}$ ratio as well as the measured particle mass over more than 16 oxidation lifetimes. The particle mass is determined from the SMPS volume multiplied by the particle density, calculated from the ratio of the vacuum aerodynamic diameter to the mobility diameter (DeCarlo et al., 2005) and is normalized to the initial particle mass. Both the particle mass and $\mathrm{O} / \mathrm{C}$ ratio measurements are compared with predictions based on the sequential oxidation model. The predicted $\mathrm{O} / \mathrm{C}$ ratio is calculated by assuming that one $\mathrm{O}$ atom is added per $\mathrm{OH}$ reaction, and the predicted mass is computed by assuming that for each $\mathrm{O}$ atom added one $\mathrm{H}$ atom is lost (i.e. carbonyls and alcohols formed in equal amounts). It should be noted that the predicted mass is primarily determined by the incorporation of $\mathrm{O}$ atoms, and the assumption about $\mathrm{H}$ atom loss has a relatively minor effect. Furthermore, the very slight non-linearity observed in the predicted $\mathrm{O} / \mathrm{C}$ ratios and mass result from the fact that as the modeled particles grow, due to incorporation of oxygen, the $\mathrm{OH}$ collision frequency also increases. It can be seen in Fig. 10 that for oxidation lifetimes $\leq 3$ the predicted mass and the measured mass are very similar. This observation suggests that only minimal volatilization, which is neglected in the oxidation model, results from the oxidation of squalane at these early lifetimes. It is over this exposure region that we perform the kinetic analysis presented above.

At oxidation lifetimes $\geq 3$ the predicted mass increasingly deviates from the measured aerosol mass indicating that volatilization becomes a progressively more important loss channel for organic material in the particle. In fact, the difference between the measured mass and the predicted mass represents an upper bound on the fraction of the particle lost to volatilization. For instance after 16 lifetimes there is approximately $50 \%$ less mass than if no volatilization had occurred. This is an upper limit estimate of volatilization because it is likely that the uptake coefficient does not remain constant over this many oxidation lifetimes. The $\mathrm{O} / \mathrm{C}$ ratio predicted

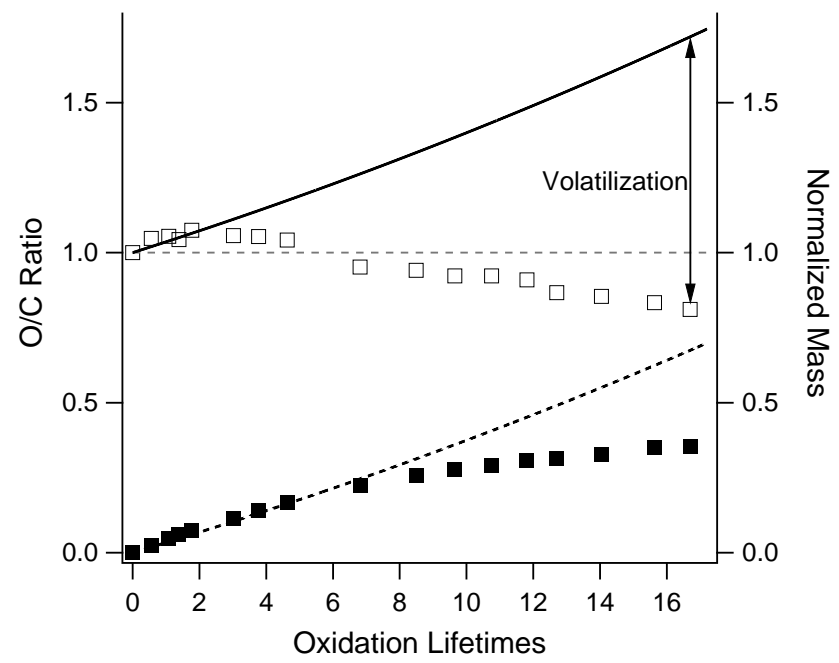

Fig. 10. O/C ratios ( $\boldsymbol{\square})$ as a function of oxidation lifetimes measured using the EI HR-TOF-AMS. The measured mass $(\square)$ is determined from the SMPS volume multiplied by the particle density, which is calculated from the ratio of the aerodynamic and mobility particle diameters. The measured data is compared with the O/C ratio (dashed line) and the particle mass (solid line) predicted from the sequential oxidation model described in the text. The upper limit for the degree of particle volatilization is simply the difference between the actual mass measured in the experiment and the predicted mass (indicated by the arrow).

by the oxidation model agrees with the measured $\mathrm{O} / \mathrm{C}$ data over a larger range (up to 6 lifetimes) than the predicted mass. This indicates that initially volatilization does not appreciably change the elemental composition of the particle. Therefore, the organic fragments which are lost to the gas-phase have the same average $\mathrm{O} / \mathrm{C}$ ratio as the non-volatile material remaining in the particle-phase. However, at oxidation lifetimes $>6$ the measured $\mathrm{O} / \mathrm{C}$ ratio deviates substantially from the predicted value. This deviation could result from a decrease in the uptake coefficient at higher lifetimes potentially in combination with a change in the particle $\mathrm{O} / \mathrm{C}$ ratio due to volatilization.

Figure 10 implies that volatilization of a significant fraction of a chemically reduced organic particle, such as squalane or a primary organic aerosol, would be very slow at atmospheric $\mathrm{OH}$ concentrations, on the order of many weeks. However, as the $\mathrm{O} / \mathrm{C}$ ratio of the particle increases the probability of an $\mathrm{OH}$ abstraction occurring adjacent to a functional group also increases, enhancing the likelihood of decomposition reactions leading to volatilization (Atkinson, 1997). This observation has important implications for the heterogeneous aging of more highly oxygenated organic particles in the atmosphere such as secondary organic aerosols (SOA). A significant fraction of the total organic aerosol mass in the atmosphere results from SOA (Zhang et al., 2007), and recent elemental composition measurements indicate that $\mathrm{O} / \mathrm{C}$ ratios for urban SOA are greater than 0.4 (Aiken et al., 
2008). The high oxygen content of SOA suggests that heterogeneous oxidation likely results in a significant degree of volatilization.

Based on the mechanism shown in Fig. 6, the only route for volatilization is through alkoxy radical decomposition (Reaction 7). Therefore, the observation of significant volatilization at high $\mathrm{O} / \mathrm{C}$ ratios strongly suggests that alkoxy (RO) radicals are an important intermediate in the oxidation of squalane particles. RO radicals are likely formed from the $\mathrm{RO}_{2}$ self reaction (Reaction 3 in Fig. 6), and subsequently decompose via C-C bond scission (Reaction 7), which is precisely the reaction that results in volatilization. The decomposition of $\mathrm{RO}$ radicals at high $\mathrm{O} / \mathrm{C}$ ratios reflects the large increase in the rate of Reaction 7 for $\beta$-substituted RO radicals (Atkinson, 1997). Therefore it is possible that RO radicals are present at lower $\mathrm{O} / \mathrm{C}$ ratios, but may not readily fragment, reacting instead via the other reaction pathways shown in Fig. 6.

For long chain RO radicals in the gas-phase, the isomerization channel (Reaction 4) is the dominant loss mechanism (Aschmann et al., 2001). Isomerization results in more than one $\mathrm{O}$ atom added per squalane reaction, which is inconsistent with the experimental data presented above. Therefore, the fate of particle-phase RO radicals is likely the reaction with $\mathrm{O}_{2}$ (Reaction 5) and/or $\mathrm{H}$ atom abstraction from neighboring molecules (Reaction 6). It should be pointed out that Reaction 6 can potentially remove squalane and lead to an effective increase in the measured uptake coefficient. The influence of this kind of secondary chemistry will be explored in an upcoming paper (Smith et al., 2009).

\section{Conclusions}

Using a photochemical flow reactor combined with AMS particle analysis, the kinetics and chemical mechanism for $\mathrm{OH}$ oxidation of squalane particles has been investigated. The reactive uptake coefficient of $\mathrm{OH}$ on squalane particles is $0.3 \pm 0.07$, indicating that $30 \%$ of the $\mathrm{OH}$-particle collisions result in a reaction. Based on the evolution of the oxidation products during the first few oxidation lifetimes it is found that one $\mathrm{O}$ atom is added per reactive loss of squalane, which is consistent with a sequential oxidation reaction mechanism. At higher oxidation lifetimes, and therefore higher $\mathrm{O} / \mathrm{C}$ ratios, the particles lose carbon leading to particle volatilization. In fact, for $\mathrm{O} / \mathrm{C}$ ratios above $\sim 0.3$ it appears that volatilization dominates, which may be particularly important for heterogeneous reactions with ambient SOA particles. These results suggest that future studies should focus on the heterogeneous reactivity of highly oxygenated, SOA-like, aerosols.

Finally, these results suggest a generalized framework to better understand the essential mechanistic differences between the heterogeneous chemistry of primary organic aerosols and the formation of SOA. SOA formation is ini- tiated by the gas-phase oxidation of VOCs followed by the partitioning of oxidation products to the aerosol-phase. In the gas-phase the fate of alkoxy radicals has been shown to be the isomerization channel, which adds an alcohol, leaving an alkyl radical on the same molecule. This alkyl radical can react with $\mathrm{O}_{2}$ to further functionalize this single molecule. As shown by Aschmann et al. (2001) this can happen two or more times, depending on the carbon chain length, resulting in many $\mathrm{O}$ atoms added per reactive loss of a hydrocarbon in the gas-phase. These molecules will eventually partition to the aerosol-phase producing a particle that may be highly enriched in oxygen. This is in direct contrast with the aerosolphase in which the primary fate of the RO is either reaction with $\mathrm{O}_{2}$ or intermolecular $\mathrm{H}$ abstraction. In this case, one $\mathrm{O}$ atom is added per reactive loss of a condensed-phase hydrocarbon. This chemical mechanism, combined with an uptake coefficient that is only 0.3 , has the net consequence that oxygen functional groups are added to organic particles relatively slowly under atmospheric conditions.

Acknowledgements. This work was supported by the Director, Office of Energy Research, Office of Basic Energy Sciences, Chemical Sciences Division of the US Department of Energy under Contract No. DE-AC02-05CH11231. J. D. S. is supported by the Camille and Henry Dreyfus foundation postdoctoral program in environmental chemistry. D. L. C. is grateful to the National Aeronautics and Space Administration for support on Grant NASA-NNG06GGF26G. S. R. L. gratefully acknowledges the generous support of a Morris Belkin Visiting Professorship at the Weizmann Institute of Science.

Edited by: M. Ammann

\section{References}

Aiken, A. C., DeCarlo, P. F., and Jimenez, J. L.: Elemental analysis of organic species with electron ionization high-resolution mass spectrometry, Anal. Chem., 79, 8350-8358, 2007.

Aiken, A. C., Decarlo, P. F., Kroll, J. H., Worsnop, D. R., Huffman, J. A., Docherty, K. S., Ulbrich, I. M., Mohr, C., Kimmel, J. R., Sueper, D., Sun, Y., Zhang, Q., Trimborn, A., Northway, M., Ziemann, P. J., Canagaratna, M. R., Onasch, T. B., Alfarra, M. R., Prevot, A. S. H., Dommen, J., Duplissy, J., Metzger, A., Baltensperger, U., and Jimenez, J. L.: O/C and OM/OC ratios of primary, secondary, and ambient organic aerosols with high-resolution time-of-flight aerosol mass spectrometry, Environ. Sci. Technol., 42, 4478-4485, 2008.

Aschmann, S. M., Arey, J., and Atkinson, R.: Atmospheric chemistry of three C-10 alkanes, J. Phys. Chem. A, 105, 7598-7606, 2001.

Atkinson, R.: Atmospheric reactions of alkoxy and betahydroxyalkoxy radicals, Int. J. Chem. Kinet., 29, 99-111, 1997.

Atkinson, R.: Kinetics of the gas-phase reactions of $\mathrm{OH}$ radicals with alkanes and cycloalkanes, Atmos. Chem. Phys, 3, 22332307, 2003.

Atkinson, R., Baulch, D. L., Cox, R. A., Crowley, J. N., Hampson, R. F., Hynes, R. G., Jenkin, M. E., Rossi, M. J., and Troe, J.: 
Evaluated kinetic and photochemical data for atmospheric chemistry: Volume I - gas phase reactions of $\mathrm{O}-\mathrm{x}, \mathrm{HO}_{\mathrm{x}}, \mathrm{NO}_{\mathrm{x}}$ and $\mathrm{SO}_{\mathrm{x}}$ species, Atmos. Chem. Phys, 4, 1461-1738, 2004.

Avila, D. V., Brown, C. E., Ingold, K. U., and Lusztyk, J.: Solvent Effects on the Competitive Beta-Scission and Hydrogen-Atom Abstraction Reactions of the Cumyloxyl Radical - Resolution of a Long-Standing Problem, J. Am. Chem. Soc., 115, 466-470, 1993.

Bagot, P. A. J., Waring, C., Costen, M. L., and McKendrick, K. G.: Dynamics of inelastic scattering of $\mathrm{OH}$ radicals from reactive and inert liquid surfaces, J. Phys. Chem. C, 112, 10868-10877, 2008.

Bennett, J. E. and Summers, R.: Product Studies of Mutual Termination Reactions of Sec-Alkylperoxy Radicals - Evidence for Non-Cyclic Termination, Can. J. Chem., 52, 1377-1379, 1974.

Bertram, A. K., Ivanov, A. V., Hunter, M., Molina, L. T., and Molina, M. J.: The reaction probability of $\mathrm{OH}$ on organic surfaces of tropospheric interest, J. Phys. Chem. A., 105, 94159421, 2001.

Broekhuizen, K. E., Thornberry, T., Kumar, P. P., and Abbatt, J. P. D.: Formation of cloud condensation nuclei by oxidative processing: Unsaturated fatty acids, J. Geophys. Res.-Atmos., 109, D24206, doi:10.1029/2004JD005298, 2004.

D’Anna, B., Andresen, W., Gefen, Z., and Nielsen, C. J.: Kinetic study of $\mathrm{OH}$ and $\mathrm{NO} 3$ radical reactions with 14 aliphatic aldehydes, Phys. Chem. Chem. Phys., 3, 3057, 2001.

DeCarlo, P. F., Slowik, J. G., Worsnop, D. R., Davidovits, P., and Jimenez, J. L.: Particle morphology and density characterization by combined mobility and aerodynamic diameter measurements. Part 1: Theory, Aerosol Sci. Tech., 39, 184-184, 2005.

DeCarlo, P. F., Kimmel, J. R., Trimborn, A., Northway, M. J., Jayne, J. T., Aiken, A. C., Gonin, M., Fuhrer, K., Horvath, T., Docherty, K. S., Worsnop, D. R., and Jimenez, J. L.: Field-deployable, high-resolution, time-of-flight aerosol mass spectrometer, Anal. Chem., 78, 8281-8289, 2006.

Docherty, K. S., and Ziemann, P. J.: Reaction of oleic acid particles with $\mathrm{NO}_{3}$ radicals: Products, mechanism, and implications for radical-initiated organic aerosol oxidation, J. Phys. Chem. A., 110, 3567-3577, 2006.

Dusek, U., Frank, G. P., Hildebrandt, L., Curtius, J., Schneider, J., Walter, S., Chand, D., Drewnick, F., Hings, S., Jung, D., Borrmann, S., and Andreae, M. O.: Size matters more than chemistry for cloud-nucleating ability of aerosol particles, Science, 312, 1375-1378, 2006.

Ferenac, M. A., Davis, A. J., Holloway, A. S., and Dibble, T. S.: Isomerization and decomposition reactions of primary alkoxy radicals derived from oxygenated solvents, J. Phys. Chem. A., 107, 63-72, 2003.

Finlayson-Pitts, B. J. and Pitts, J. N.: Chemistry of the Upper and Lower Atmosphere, Academic press, San Diago, CA, 2000.

Fokin, A. A., and Schreiner, P. R.: Selective alkane transformations via radicals and radical cations: Insights into the activation step from experiment and theory, Chem. Rev., 102, 1551-1593, 2002.

Fuchs, N. A. and Sutugin, A. G.: Highly Dispersed Aerosols, Butterworth-Heinemann, Newton, MA, 1970.

George, I. J., Vlasenko, A., Slowik, J. G., Broekhuizen, K., and Abbatt, J. P. D.: Heterogeneous oxidation of saturated organic aerosols by hydroxyl radicals: uptake kinetics, condensed-phase products, and particle size change, Atmos. Chem. Phys., 7, 4187-4201, 2007, http://www.atmos-chem-phys.net/7/4187/2007/.

Gloaguen, E., Mysak, E. R., Leone, S. R., Ahmed, M., and Wilson, K. R.: Investigating the chemical composition of mixed organicinorganic particles by "soft" vacuum ultraviolet photoionization: The reaction of ozone with anthracene on sodium chloride particles, Int. J. Mass Spectrom., 258, 74-85, 2006.

Hearn, J. D., Lovett, A. J., and Smith, G. D.: Ozonolysis of oleic acid particles: evidence for a surface reaction and secondary reactions involving Criegee intermediates, Phys. Chem. Chem. Phys., 7, 501-511, 2005.

Hearn, J. D. and Smith, G. D.: A mixed-phase relative rates technique for measuring aerosol reaction kinetics, Geophys. Res. Lett., 33, L17805, doi:10.1029/2006GL026963, 2006.

Hearn, J. D., Renbaum, L. H., Wang, X., and Smith, G. D.: Kinetics and products from reaction of $\mathrm{Cl}$ radicals with dioctyl sebacate (DOS) particles in O2: a model for radical-initiated oxidation of organic aerosols, Phys. Chem. Chem. Phys., 9, 4803-4813, 2007.

Ingold, K. U.: Peroxy Radicals, Acc. Chem. Res., 2, 1-2, 1969.

Kanakidou, M., Seinfeld, J. H., Pandis, S. N., Barnes, I., Dentener, F. J., Facchini, M. C., Van Dingenen, R., Ervens, B., Nenes, A., Nielsen, C. J., Swietlicki, E., Putaud, J. P., Balkanski, Y., Fuzzi, S., Horth, J., Moortgat, G. K., Winterhalter, R., Myhre, C. E. L., Tsigaridis, K., Vignati, E., Stephanou, E. G., and Wilson, J.: Organic aerosol and global climate modelling: a review, Atmos. Chem. Phys, 5, 1053-1123, 2005.

Katrib, Y., Biskos, G., Buseck, P. R., Davidovits, P., Jayne, J. T., Mochida, M., Wise, M. E., Worsnop, D. R., and Martin, S. T.: Ozonolysis of mixed oleic-acid/stearic-acid particles: Reaction kinetics and chemical morphology, J. Phys. Chem. A., 109, 10910-10919, 2005.

Kwan, A. J., Crounse, J. D., Clarke, A. D., Shinozuka, Y., Anderson, B. E., Crawford, J. H., Avery, M. A., McNaughton, C. S., Brune, W. H., Singh, H. B., and Wennberg, P. O.: On the flux of oxygenated volatile organic compounds from organic aerosol oxidation, Geophys. Res. Lett., 33, L15815, doi:10.1029/2006GL026144, 2006.

Lambe, A. T., Zhang, J. Y., Sage, A. M., and Donahue, N. M.: Controlled $\mathrm{OH}$ radical production via ozone-alkene reactions for use in aerosol aging studies, Environ. Sci. Technol., 41, 23572363, 2007.

McNeill, V. F., Yatavelli, R. L. N., Thornton, J. A., Stipe, C. B., and Landgrebe, $\mathrm{O} .:$ The heterogeneous $\mathrm{OH}$ oxidation of palmitic acid in single component and internally mixed aerosol particles: vaporization, socondary chemistry, and the role of particle phase, Atmos. Chem. Phys, 8, 5465-5476, 2008.

Molina, M. J., Ivanov, A. V., Trakhtenberg, S., and Molina, L. T.: Atmospheric evolution of organic aerosol, Geophys. Res. Lett., 31, L22104, doi:10.1029/2004GL020910, 2004.

Paltenghi, R., Ogryzlo, E. A., and Bayes, K. D.: Rates of Reaction of Alkyl Radicals with Ozone, J. Phys. Chem., 88, 2595-2599, 1984.

Rudich, Y., Donahue, N. M., and Mentel, T. F.: Aging of organic aerosol: Bridging the gap between laboratory and field studies, Annu. Rev. Phys. Chem., 58, 321-352, 2007.

Russell, G. A.: Solvent Effects in the Reactions of Free Radicals and Atoms, J. Am. Chem. Soc., 79, 3871-3877, 1957.

Seinfeld, J. H. and Pandis, S. N.: Atmospheric Chemistry and Physics, Wiley, New York, 1998.

Shilling, J. E., King, S. M., Mochida, M., and Martin, S. T.: Mass 
spectral evidence that small changes in composition caused by oxidative aging processes alter aerosol CCN properties, J. Phys. Chem. A, 111, 3358-3368, 2007.

Smith, J. D., Cappa, C. D., Che, D. L., Liu, C., Ahmed, M., Leone, S. R., and Wilson, K. R.: An investigation of secondary chemistry initiated by the $\mathrm{OH}$ oxidation of organic aerosols., in preparation, 2009.

Vlasenko, A., George, I. J., and Abbatt, J. P. D.: Formation of volatile organic compounds in the heterogeneous oxidation of condensed-phase organic films by gas-phase OH, J. Phys. Chem. A, 112, 1552-1560, 2008.

Vonsonntag, C., and Schuchmann, H. P.: The Elucidation of Peroxyl Radical Reactions in Aqueous-Solution with the Help of Radiation-Chemical Methods, Angew. Chem., Int. Edit., 30, 1229-1253, 1991.
Zhang, Q., Jimenez, J. L., Canagaratna, M. R., Allan, J. D., Coe, H., Ulbrich, I., Alfarra, M. R., Takami, A., Middlebrook, A. M., Sun, Y. L., Dzepina, K., Dunlea, E., Docherty, K., DeCarlo, P. F., Salcedo, D., Onasch, T., Jayne, J. T., Miyoshi, T., Shimono, A., Hatakeyama, S., Takegawa, N., Kondo, Y., Schneider, J., Drewnick, F., Borrmann, S., Weimer, S., Demerjian, K., Williams, P., Bower, K., Bahreini, R., Cottrell, L., Griffin, R. J., Rautiainen, J., Sun, J. Y., Zhang, Y. M., and Worsnop, D. R.: Ubiquity and dominance of oxygenated species in organic aerosols in anthropogenically-influenced Northern Hemisphere midlatitudes, Geophys. Res. Lett., 34, L13801, doi:10.1029/2007GL029979, 2007. 